\title{
Myths vs. Facts about Child Sexual Abuse and Prevention Education
}

\author{
Andrea Donitta. G., M.SC (N) \\ Nursing Tutor, Department of Psychiatric Nursing, M. A. Chidambaram College of Nursing, Chennai, India
}

1) MYTH: "Wow, we live in a really safe neighborhood. In fact, we searched long and hard for the SAFEST neighborhood we could find! We know ALL our neighbors, and feel comfortable that everyone is looking out for each other. I KNOW that my children wouldn't ever be sexually abused here! I care about my kids - I keep them safe!"

FACT: Child sexual abuse happens to children everywhere in every neighborhood, in every church group, in every racial and cultural group, no matter how rich or poor we are, no matter how many of our neighbors we know, or don't know, personally. Sadly, national statistics reported by the U.S. Dept. of Justice say that as many as 1 out of 3 little girls, and as many as 1 out of 5 little boys, may be sexually abused by the time they're 18. And elementary age children are the most vulnerable to being hurt this way. Children with disabilities are even more at risk. BOTTOM LINE: All of our children are at risk for being victimized by sexual abuse, or sexual harassment - and are especially vulnerable if they're uneducated about it, or unaware that it could even happen at all!

2) МYTH: "I've already talked with my kids about sexual abuse, and told them never to let any grownup touch their private body parts. I know my child won't let a grownup do this, and I know it could NEVER happen at their school!"

FACT: Sexual abuse happens when someone FORCES a child, or TRICKS a child, so that the other person can touch the child's private body parts, or so that the child will touch the other person's priva te body parts. Children can do this, grownups can do this, teen-agers can do this. Sexual abuse is about forcing or manipulating a child - so they are confused and really don't understand what's going on. (It's not as though the abuser asks the child, "Wou ld you mind if I sexually abuse you?" and the child says, "Sure, go ahead. I'll let you!') The offender will say to the child something like, "This is what people do when they love each other." In the prevention field, this manipulation is called GROOMING the child - a process where the abuser is getting ready, or preparing the child, for the sexual abuse to take place. Another component of the GROOMING process is to ensure the self-protection of the abuser - to ensure that the child will not tell.. And unfortunately, even the child's family and community can be GROOMED by the child sexual abuse offender. Many times, the perpetrator fools families and other members of the local community into thinking that he or she is such a good person, in such good standing in the community, that of course they would never have done this terrible crime of sexual abuse! And many times, the children who are victims of the crime of sexual abuse are unhappily left struggling to feel believed by someone they love or trust that this terrible thing, the sexual abuse, actually did happen to them.

3) MYTH: "Most sexual abuse is committed by someone who's a stranger to the child."

FACT: Someone the child knows, likes, trusts and loves, and/or lives with is the person most likely to sexually abuse a child. Usually, perpetrators of sexual abuse are not strangers to the children they abuse. They may be a relative, friend, baby-sitter, people who are in charge of a child such as a teacher, or other care providers - such as camp counselors or other youth group leaders. The majority of children who are sexually abused know their abuser.

When we talk with our children about this difficult problem of child sexual abuse, we adults need to know this - it can happen, and does happen, to children from other children and from teen-agers, too. So, yes, it can happen at school! When we are talking to our children about this problem, we need to remember that sexual abuse is not only when someone gets raped - although yes, that is sexual abuse. But sexual abuse also happens to children in lots of other ways such as when someone takes pictures of a child without clothes on, and posts those pictures on a website; or when someone flashes or exposes themselves to the child; or when someone talks or gestures in a sexually suggestive way to the child; or when someone touches the child in a sexual way.

4) MYTH: "I'm SO lucky - my child and I have SUCH a great relationship! My child feels comfortable talking with me about everything. I KNOW my child would tell me - and right away! - if he or she was ever touched in a sexual way, or otherwise sexually abused or sexually threatened!"

FACT: If it happens to them, most children never tell about their abuse. Most children are afraid that this news will hurt their parents in some way, or are afraid that no one would believe what happened to them, or are afraid that no one would believe that the person who abused them actually did that. Also, most children tell the truth about sexual abuse. Most children don't know enough about the sexual activity they report to be fabricating. The younger the child is when they are sexually abused, or when they tell about being sexually abused, the likelier it is that their report is true. 


\section{International Journal of Science and Research (IJSR) \\ ISSN (Online): 2319-7064 \\ Index Copernicus Value (2013): 6.14 | Impact Factor (2014): 5.61}

5) MYTH: "I worry about sexual abuse with my little girl but I really think my boys can take care of themselves. They'll be safe, I know!"

FACT: The fact is, that sexual abuse happens to boys as well as girls. And when it does happen to little boys, very often they think that they should have been able to stop it, or to protect themselves. So they feel angry, or sad, and ashamed, and blame themselves - just like girls do. And again, the fact is, that child sexual abuse is NEVER the child's fault, whether they are a girl, or a boy. Children do not have the innate power to stop the abuser, if that person is intent on harming the child. But ALL children deserve to learn body safety rules about sexual abuse that they can use to help themselves keep safe from abuse, bullying or sexual harassment.

6) MYTH: "My kids already had a short, in-school puppet show presentation about sexual abuse. They heard it last year! Why would they need to hear that again? Let's move on, and get back to learning the really important things!'

FACT: One-shot deals, such as puppet shows, can be very entertaining to children, but they should NEVER be confused with effective prevention education. Learning and developmental growth theories such as those of Erickson, Piaget or Kohlberg show us that children learn and develop mentally, morally and physically at all different rates, and through different stages. Whatever your children heard in school during the one-time puppet show presentation isn't nearly comprehensive enough, or repetitive enough, for them to absorb and process all they need to learn at each developmental level about this serious subject of sexual abuse!

And the fact remains that children can have a very hard time paying attention at school, and learning about other subjects, if they are being abused, bullied or threatened by someone. Safe environments are vital to children's learning success so abuse prevention education is a critical component for every school's curriculum each year.

\section{Other Myths about Child Sex Abuse (CSA)}

There are a lot of misconceptions around this issues.

Following is a collection of some:

MYTH 1: CSA is a rare thing

Truth: about $15-20 \%$ adults report receiving some form of sex abuse as kids. This abuse ranges from inappropriate and repeated touching to penetrative sex. Abuse almost always starts with inappropriate talk and touch before progressing to worse things.

MYTH 2: CSA only happens in western countries

Truth: Scientific research has proved that CSA is prevalent in all cultures, languages, countries and religions. There are no countries where CSA is not reported. There are differences in legal age for consensual sex in various countries but CSA as defined by local law is found EVERYWHERE!
MYTH 3: In India, CSA happens only in slums

Truth: Though children from lower socio-economic class are more vulnerable to CSA, it is by no means exclusive to that group. Kids from all levels of society are affected.

MYTH 4: CSA happens only with girls

Truth: Till age of 12, boys and girls are equally affected. After adolescence girls are more affected than boys.

MYTH 5: CSA happens with kids of troubled and broken families.

Truth: Though kids in troubled families are more likely to be abused, they are not the only ones. Kids from stable families are abused too ! Having an intact and untroubled family helps children to recover better from abuse but it does not protect them if they are not armed with the knowledge of UNSAFE TOUCH.

MYTH 6: Abusers are social misfits and easily identifiable Truth: almost all abusers look just like you and me. There is no definite way of identifying an abuser from looks alone. Many abusers are family men with children and respectable professions like doctors, priests, teachers, etc.

\section{MYTH 7: Abusers are always strangers to the kids}

Truth: This is one of the most dangerous myth. $70 \%$ of abusers are directly related to the child. They are family members. Another $20 \%$ are well known to the family and have free access to kids, e.g. family friends, teachers, neighbours, etc.

\section{References}

[1] Ceci, S. J., \& Bruck, M. (1993). The suggestibility of the child witness: A historical review and synthesis. Psychological Bulletin, 113 , 403-39.

[2] Everson, M.D., \& Boat, B. W. (1989). False allegations of sexual abuse by children and adolescents. Journal of the American Academy of Child and Adolescent Psychiatry. 28 : 230-5.

[3] Jones, D. P. H., \& McGraw, J. M. (1987). Reliable and fictitious accounts of sexual abuse to children. Journal of Interpersonal Violence, 2, 27-45.

[4] Lawson, L., \& Chaffin, M. (1992). False negatives in sexual abuse disclosure interviews. Journal of Interpersonal Violence, 7 , 532-42.

[5] Lyon, T.D. (1999). The new wave of suggestibility research: A critique. Cornell Law Review, 84, 10041087.

[6] Lyon, T.D. (2001). Let's not exaggerate the suggestibility of children. Court Review, 28 (3), 12-14. (on-line: http://aja.ncsc.dni.us/courtrv/cr38-3/CR383Lyon.pdf )

[7] Lyon, T.D. (2002). Scientific Support for Expert Testimony on Child Sexual Abuse Accommodation. In J.R. Conte (Ed.), Critical issues in child sexual abuse (pp. 107-138). Newbury Park, CA: Sage. (on-line: http://www.law.duke.edu/shell/cite.pl?65+Law+\&+Con temp.+Probs.+97+(Winter+2002 )

[8] Oates, R. K., Jones, D. P., Denson, D., Sirotnak, A., Gary, N., \& Krugman, R. D. (2000). Erroneous concerns about child sexual abuse. Child Abuse \& Neglect, 24 , 149-57. 


\section{International Journal of Science and Research (IJSR) \\ ISSN (Online): 2319-7064 \\ Index Copernicus Value (2013): 6.14 | Impact Factor (2014): 5.61}

[9] Pezdek, K., \& C. Roe. (1997). The suggestibility of children's memory for being touched: Planting, erasing, and changing memories. Law and Human Behavior, 21, 95-106.

[10] Saywitz, K. J., Goodman, G. S., Nicholas, E., \& Moan, S. F. (1991). Children's memories of a physical examination involving genital touch: Implications for reports of child sexual abuse. Journal of Consulting \& Clinical Psychology, 59 , 682-91.

[11] Sjoberg, R. L., \& Lindblad, F. (2002). Limited disclosure of sexual abuse in children whose experiences were documented by videotape. American Journal of Psychiatry, 159 , 312-4.

\section{Author Profile}

Andrea Donitta. G., M.SC (N), is Nursing Tutor, Department of Psychiatric Nursing, M. A. Chidambaram College of Nursing, Chennai, India 